Vol. 1 No. 1 2018, Hal. 43-54

\title{
FRAMING MEDIA ONLINE ATAS PEMBERITAAN ISU POLITIK UANG DALAM PILKADA SERENTAK 2018
}

\author{
Lestari Nurhajati \\ Stikom LSPR (The London School of Public Relations) Jakarta, Indonesia \\ Lestari.n@lspr.edu \\ Xenia Angelica Wijayanto \\ Stikom LSPR (The London School of Public Relations) Jakarta, Indonesia \\ Xenia.aw@Ispr.edu
}

\begin{abstract}
Money politics is one of the issues that has always been a problem in the process of electing Regional Heads (Pilkada), including in the Pilkada on June 27, 2018. All parties involved in the election process, both voters, Election Management Bodies (KPU) and Bawaslu, always see that the case of money politics is a problem that seems never resolved, and recurs from year to year. Moreover, the mass media, including online media always discuss the issue of money politics in Pilkada activities in Indonesia. This study aims to find out how the online media in Indonesia conducts framing news in the issue of money politics, especially in the 2018 Simultaneous Regional Election. Framing theory in media reporting becomes interesting to study because this theory sees that the issue by media perspective in reporting becomes important value for the media readers. Media audiences can be directly and indirectly affected by various news framing by the media. Qualitative methods with Entman's framing approach are used to analyze framing in 5 online media with the most access in Indonesia, they are: Tribunnews.com, Detik.com, Liputan6.com, Kompas.com, and Sindonews. com. The results of this study indicate that in general the media has framing that is not much different. It's just in the parts of treatment recommendation it appears that the media does not explicitly show their alignment with regulations and ethics which is clearly prohibit the practice of money politics in the elections.
\end{abstract}

Keywords: Pilkada, Money Politic, Framing, Online Media 


\begin{abstract}
Abstrak
Politik uang menjadi salah satu isu yang selalu menjadi persoalan dalam proses pemilihan Kepala Daerah (Pilkada), termasuk dalam Pilkada 27 Juni 2018 lalu. Semua pihak yang terlibat dalam proses Pilkada ini, baik pemilih maupun penyelenggara pemilu, selalu melihat bawa kasus politik uang ini menjadi persoalan yang seolah tidak pernah terselesaikan, dan terjadi berulang dari tahun ke tahun. Permasalahan yang muncul adalah media massa, termasuk media online selalu membahas isu politik uang dalam kegiatan Pilkada di Indonesia. Penelitian ini bertujuan untuk mengetahui bagaimana sesungguhnya media online di Indonesia melakukan framing (pembingkaian) berita dalam isu politik uang, terutama dalam kegiatan Pilkada Serentak 2018. Teori Framing pada pemberitaan media menjadi menarik dikaji karena teori ini melihat bahwa sudut pandang media dalam memberitakan sebuah isu menjadi penting nilainya bagi para pembaca media tersebut. Khalayak media bisa secara langsung dan tak langsung terpengaruh dengan berbagai pembingkaian berita oleh media. Metode kualitatif dengan pendekatan framing Entman digunakan untuk menganalisa framing di 5 media online dengan pengakses terbanyak di Indonesia yakni Tribunnews.com, Detik.com, Liputan6.com, Kompas.com, dan Sindonews.com. Hasil penelitian ini menunjukan bahwa secara umum media memiliki framing yang tidak jauh berbeda. Hanya saja pada bagian saran perbaikan, tampak media tidak secara tegas menunjukan sikap keberpihakannya pada regulasi dan etika yang secara jelas melarang praktik politik uang dalam Pilkada.
\end{abstract}

Keywords: Pilkada, Politik Uang, Framing, Media Online

\section{Pendahuluan}

Politik uang menjadi salah satu isu yang selalu menjadi persoalan dalam proses pemilihan Kepala Daerah (Pilkada), termasuk dalam Pilkada 27 Juni 2018 lalu. Semua pihak yang terlibat dalam proses Pilkada ini, baik pemilih maupun penyelenggara pemilu, selalu melihat bawa kasus politik uang ini menjadi persoalan yang seolah tidak pernah terselesaikan, dan terjadi berulang dari tahun ke tahun. Terlebih media massa, termasuk media online selalu membahas isu politik uang dalam kegiatan Pilkada di Indonesia. Meskipun isu politik uang sudah berlangsung cukup lama, namun peneliti memilih Pilkada 2018 sebagai kajian dengan data terkini yang bisa diakses.

Media online menarik untuk dibahas dikarenakan saat ini sudah terjadi perubahan pola konsumsi media terutama pada generasi muda. Perubahan tersebut secara drastis menunjukkan pola media cetak sudah mulai ditinggakan pembacanya yang beralih ke media online (Nurhajati, 2015). Padahal generasi muda juga menjadi salah satu pemilih dengan suara yang cukup signifikan. Meski 
demikian tidak menutup kemungkinan secara umum khalayak luas dari berbagai usia, juga makin aktif mengkonsumsi pemberitaan di media online.

Pemberitaan di media, dalam hal ini media online, juga bisa menjadi salah satu sarana pembentukan opini publik. Dalam ranah komunikasi politik ini disebut dengan Bandwagon Effect Theory (Nadeu, 1993). Teori ini menjelaskan bagaimana seseorang berusaha menyesuaikan diri dengan pendapat mayoritas orang banyak di sekitarnya. Pendapat umum di sekitarnya itu terjadi akibat terpaan media secara kuat dan kontinyu sehingga dipercaya kebenarannya. Seseorang berpikir agar tidak terisolasi atau dianggap berbeda pendapat dan sikapnya maka ia memilih mengikuti pendapat umum orang-orang di sekitarnya. Media kemudian dianggap memiliki kekuatan luar biasa untuk membentuk opini publik.

Pentingnya memahami bagaimana media online berkaitan dengan khalayak luas, salah satunya bisa dilihat dari proses terjadinya terpaan media (media exposure). Terpaan media ini sebuah kondisi yang secara mendalam menggambarkan bagaimana media bisa sangat mempengaruhi khalayak terutama ketika tingginya frekuensi media tersebut dikonsumsi oleh seseorang.

Ada lima media online yang akan dikaji dalam penelitian ini, yakni Tribunnews.com, Detik.com, Liputan6. com, Kompas.com, dan Sindonews. com. Pemilihan kelima media tersebut berdasarkan banyaknya orang mengakses dan menggunakan media online tersebut. Hal ini bisa kita ketahui melalui ranking Alexa.com yang secara periodik menunjukan posisi peringkat media online di Indonesia, berdasarkan banyaknya orang yang mengakses media online tersebut. Posisi peringkat tersebut tentu saja bisa berubah dari waktu ke waktu. Alexa.com adalah situs pencatat ranking urutan media online yang paling sering/ banyak dibaca oleh masyarakat di sebuah Negara atau pun sebuah wilayah. Situs ini merupakan situs terpercaya untuk membuat ranking posisi media online disamping situs google rank.

Tabel 1. 20 Besar Situs/ Portal Menurut Alexa.com

\begin{tabular}{|l|c|c|c|}
\hline \multicolumn{1}{|c|}{$\begin{array}{c}\text { Nama } \\
\text { Media }\end{array}$} & $\begin{array}{c}\text { Rank- } \\
\text { ing } \\
\text { Alexa }\end{array}$ & Nama Media & $\begin{array}{c}\text { Rank- } \\
\text { ing } \\
\text { Alexa }\end{array}$ \\
\hline Google.com & 1 & Twitter.com & 11 \\
\hline $\begin{array}{l}\text { Tribunnews. } \\
\text { com }\end{array}$ & 2 & $\begin{array}{c}\text { Sindonews. } \\
\text { com }\end{array}$ & 12 \\
\hline $\begin{array}{l}\text { Youtube. } \\
\text { com }\end{array}$ & 3 & $\begin{array}{c}\text { Facebook. } \\
\text { com }\end{array}$ & 13 \\
\hline $\begin{array}{l}\text { Google. } \\
\text { co.id }\end{array}$ & 4 & Uzone.id & 14 \\
\hline $\begin{array}{l}\text { Tokopedia. } \\
\text { com }\end{array}$ & 5 & Kaskus.co.id & 15 \\
\hline Detik.com & 6 & Okezone.com & 16 \\
\hline $\begin{array}{l}\text { Bukalapak. } \\
\text { com }\end{array}$ & 7 & Kumparan. & 17 \\
\hline $\begin{array}{l}\text { Liputan6. } \\
\text { com }\end{array}$ & 8 & Grid.id & 18 \\
\hline $\begin{array}{l}\text { Blogspot. } \\
\text { com }\end{array}$ & 9 & Indoxx1.com & 19 \\
\hline $\begin{array}{l}\text { Kompas. } \\
\text { com }\end{array}$ & 10 & Merdeka.com & 20 \\
\hline
\end{tabular}

Sumber: http://www.alexa.com/topsites/ countries/ID; diakases pada 08/08/2018 - 14.03 WIB.

Di samping keberadaan media, maka posisi kepemilikan media (media ownership) dan keterampilan jurnalisnya juga memegang peran dalam proses framing tersebut nantinya. Sebuah studi yang dilakukan oleh Willnat (2013) menunjukkan bahwa kompetensi jurnalis/ wartawan yang melaporkan sebuah 
berita, sebenarnya berkorelasi dengan kualitas produk berita yang mereka hasilkan sehingga tampak persoalan media framing ini menjadi cukup komplek.

\section{Metode Penelitian}

Penelitian ini menggunakan metodologi kualitatif dengan pendekatan framing. Framing adalah pendekatan untuk mengetahui bagaimana perspektif atau cara pandang yang digunakan jurnalis ketika menyeleksi isu dan menulis berita. Perspektif tersebut akan menentukan fakta apa yang diambil, bagian mana yang hendak ditonjolkan atau bahkan dihilangkan, serta kemana arah pemberitaan tersebut (D'Angelo, 2010). Pada penelitian ini akan coba dikaji lebih lanjut bagaimana media online yang diteliti menunjukan pola pemberitaannya, termasuk apakah mereka mampu menjalankan fungsinya sebagai media yang menyajikan berita secara objektif dan bertindak sebagai pilar ke empat dalam kehidupan demokrasi.

Dalam hal ini peneliti kemudian akan mengkaji pada beberapa sampel pemberitaan yang ada di media online: Tribunnews.com, Detik.com, Liputan6. com, Kompas.com, dan Sindonews.com. Dengan cara mencari pemberitaannya melalui mesin pencari di masing-masing portal berita dengan penekanan pada isu yang memiliki relevansi dari kata kunci: "politik uang pilkada 2018". Berita dikumpulkan dari tanggal 7 April 2018 (sebelum pilkada 2018) sampai 7 September 2018 atau 6 bulan.

Sementara itu apabila kita melihat pendekatan framing juga tampak jelas bahwa media massa di Indonesia, khususnya pada para jurnalis dan jajaran redaksinya, dalam mengkonstruksi suatu realitas, mereka juga cenderung menyertakan pengalaman serta pengetahuannya yang sudah mengkristal menjadi skemata interpretation. Dengan skemata ini pula jurnalis cenderung membatasi atau menyeleksi sumber berita, menafsirkan komentar-komentar sumber berita, serta memberi porsi yang berbeda terhadap perspektif yang muncul di media (Sobur, 2004). Kondisi seperti ini perlu juga diamati dalam penelitian kali ini, pada kelima media online yang akan ditelaah.

Framing yang digunakan untuk menganalisa penelitian ini adalah framing teknik Entman.

Tabel 2. Analisa Framing

Robert N. Entman.

\begin{tabular}{|l|}
\hline $\begin{array}{l}\text { Problem Identification } \\
\text { (Peristiwa dilihat sebagai apa) }\end{array}$ \\
\hline $\begin{array}{l}\text { Causal Interpretation } \\
\text { (Siapa penyebab masalah) }\end{array}$ \\
\hline $\begin{array}{l}\text { Moral Evaluation } \\
\text { (Penilaian atas penyebab masalah) }\end{array}$ \\
\hline $\begin{array}{l}\text { Treatment Recommendation } \\
\text { (Rekomendasi atas penanggulangan } \\
\text { masalah) }\end{array}$ \\
\hline
\end{tabular}

Sumber: Eriyanto, 2011

\section{Perspektif Teori}

Salah satu teori utama yang digunakan dalam penelitian ini adalah tentang media online. Perkembangan media online memang sungguh dahsyat, dengan teknologi ini maka perpindahan informasi berjalan sangat cepat. Sehingga menurut Balnaves, Donald, \& Shoesmith (2009), menjadikan dunia ini sangat menglobal dan tidak ada lagi monopoli pengetahuan oleh salah satu pihak. Masyarakat luas, termasuk masyarakat dunia, bisa bertukar informasi dan pengetahuan satu sama 
lain, tidak ada lagi penguasaan informasi oleh segelintir individu. Dengan demikian semua orang memiliki kesempatan yang sama pula untuk menyampaikan pesan dan pendapatnya keberbagai penjuru dunia $\mathrm{Hal}$ serupa dikatakan oleh Burton (2009) yang menjabarkan adanya distribusi kekuatan ketika konvergen pada media digital terjadi. Media digital sebagai pengembangan dari media konvensional kemudian seolah sekadar mengcopy pemberitaan yang ada di suratkabar maupun televisi sebagai media utama. Namun dalam perkembangannya kemudian tak jarang media online, terutama portal berita online - news online, kemudian menjadi trendsetter pemberitaan. Karena kehadiran sangat cepat, meskipun tidak mendalam. Meskipun sesungguhnya keberadaan media digital haruslah menyesuaikan dengan kondisi tekhnologi yang ada, termasuk merubah pola komunikasinya seiring dengan perubahan khalayaknya.

Straubhaar (2006) melihat bahwa ada 3 hal utama (dari 8 karakteristik) media baru yang perlu mendapat perhatian yakni: yang pertama bersifat Innovative. Media baru diciptakan, digunakan, diadaptasi serta diserap ke dalam budaya dengan kecepatan yang sangat tinggi. Demikian cepatnya, sulit untuk menebak apa dampaknya pada budaya dan masyarakat. Yang kedua bersifat Convergent. Segala isi dan jenis pesan mulai dari gagasan, gambar, suara, brand, serta hubungan bisa disampaikan melalui segala jenis channel media. Yang ketiga bersifat Everyday. Teknologi yang semakin maju membuat media selalu berada di sekeliling kita setiap saat. Media menjadi sangat dekat dan bahkan berintegrasi dengan kehidupan manusia
Kecepatan media online dalam menyebarkan berita, serta gencarnya pemberitaan isu politik yang dibahas di media online, menjadikan pemberitaan di media online menjadi sangat potensial untuk membentuk opini publik. Kekuatan media yang sangat besar, dianggap akan mampu membentuk orang untuk memiliki persepsi yang sama atas sebuah isu politik. Dalam penelitian ini nantinya isu tentang politik uang dalam proses pilkadi 2018.

Selain teori tentang media online, ada teori lain yang penting menjadi dasar penelitian ini, yakni teori tentang framing. Robert N. Entman mendefinisikan framing sebagai seleksi dari berbagai aspek realitas yang diterima dan membuat peristiwa itu lebih menonjol dalam suatu teks komunikasi. Dalam banyak hal seperti menyajikan secara khusus definisi terhadap masalah (define problem), interpretasi sebab akibat (causal interpretation), evaluasi moral (moral evaluation) dan tawaran penyelesaian (treatment recomendation) (Eriyanto, 2011).

Media framing yang bisa disebut juga sebagai pembingkaian media adalah cara lain untuk mempengaruhi suatu fenomena atau masalah. Pembingkaian memungkinkan semua orang memiliki pemahaman mereka sendiri terhadap informasi, berita, dan bentuk penafsiran lainnya. Namun di sisi lain pembingkaian media juga berhasil meyakinkan khalayak atas apa yang harus dipercaya dan apa yang tidak percaya, sehingga seolah mampu menggiring orang untuk mempercayai sebuah berita dari sudut pandang media tersebut. Penggunaan teori framing adalah untuk mengungkapkan adakah pesan tertentu dalam sebuah 
arah berita yang terjadi dengan artikel yang dibuat oleh media. Untuk dapat memahami ke mana arah dalam artikel tertentu tersebut, peneliti juga harus memahami dan mencari tahu latar belakang medianya, untuk membantu memahami situasi sepenuhnya. Proses pembangunan opini publik melalui media framing sangatlah mungkin dilakukan.

Tidak mudah melepaskan proses pembingkaian media dengan keberadaan jurnalis/wartawannya. Dinamika jurnalis yang bersifat partisan, tidak terlepas dari bagaimana proses framing itu terjadi, kemudian bagaimana pengaturan agenda (agenda setting) dijalankan, serta bagaimana posisi dan hubungan antara jurnalis dengan narasumbernya (Cross, 2007). Dari sini menjadi erat kaitannya apabila kita melihat proses politik elektoral yang terjadi di Indonesia, termasuk dalam Pilkada 2018, tidak bisa dipisahkan dengan berbagai pemberitaan yang ada. Menjadi sangat mungkin pemberitaan yang dibingkai oleh media, dalam hal ini media online sangat dipengaruhi oleh pemahaman jurnalis dan kebijakan media yang menerbitkannya.

Dalam artikelnya, Mishra, S (2013) mengutip dari McCombs \& Reynolds, (2009), bahwa media berita dikatakan memiliki kekuatan yang sangat besar untuk mempengaruhi agenda publik dengan cara memfokuskan berita pada beberapa isu tertentu dan membuat isu tersebut tetap beredar. Ini erat kaitannya dengan konsep agenda setting yang berhubungan juga dengan konsep framing yang dideskripsikan dengan "to select and highlight some aspect of a perceived reality and enhancing the salience of an interpretation and evaluation of that reality" (Entman, 2003, p. 26).
Framing sebagai sebuah teori sekaligus metode, pada akhirnya harus dipahami dengan lebih mendalam, terutama apabila digunakan dalam sebuah pemberitaan. Menurut Entman (2003) dari empat fungsi framing di atas, maka dua yang paling atas adalah yang paling penting, yakni definisi terhadap masalah (define problem) yang sering hampir menentukan sisa dari kerangka dan rekomendasi penyelesaian (treatment recomendation) karena langsung mempromosikan dukungan (atau oposisi) untuk masalah yang ada.

\section{Hasil dan Pembahasan}

Pembahasan pada penelitian ini kemudian mencoba melihat temuan bagaimana pemberitaan di masingmasing media online yang diteliti.

Pemberitaan yang disampaikan oleh Tribunnews.com berjudul: "Polri Usut 25 Kasus Politik Uang Dalam Pilkada Serentak 2018" (Kamis, 19 Juli, 2018). Pada pemberitaan ini master frame atau bingkai utamanya apabila dilihat dari define problems atau problem identification maka tampak bahwa Tribunnews.com berusaha menunjukan bingkai bahwa Kapolri menyatakan ada 25 kasus politik uang dalam Pilkada serentak 2018 di depan rapat kerja dengan Komisi III DPR RI. Sementara kalau dilihat dari diagnose causes atau causal interpretation (perkiraan penyebab masalah), maka tampak bahwa jurnalis Tribunnews.com tidak menjelaskan apa yang menyebabkan Kapolri mengeluarkan pernyataan tersebut. Pada pembahasan make moral judgement atau moral evaluation (penilaian atas moral) media menyatakan bahwa dengan upaya polri diharapkan bahwa akan menimbulkan 
efek deterrent pada pelaku money politic lainnya. Sayangnya pada tulisan di media ini istilah efek deterrent, tidak diterjemahkan atau dijelaskan apa maksudnya. Apabila dibaca dari makna semantiknya memiliki arti sebegai efek gentar, ataupun efek jera. Pada telaah treatment recommendation (rekomendasi penyelesaian masalah), pada elemen ini peneliti bisa menilai bagaimana jurnalis menghendaki proses penyelesaian masalah. Atau jalan apa yang disarankan oleh jurnalis sebagai solusi masalah ataupun rekomendasi penyelesaian masalah. Dalam hal ini Tribunnews. com tidak memberikan rekomendasi penanggulangan masalah pada artikel ini. Posisi Tribunnews.com yang merupakan anak perusahaan Kompas, ternyata memiliki kebijakan yang jauh berbeda dengan kebijakan redaksi Kompas itu sendiri. Sehingga tampak bahwa meski judul beritanya lumayan provokatif, dalam dalam pemberitaannya, pembingkaiannya tidaklah terlalu kuat mengarahkan pada inti perspalan pemberitaan tersebut, yakni tidak lebih mendalam mengekspose 25 kasus politik uangnya.

Sementara itu untuk pemberitaan yang disampaikan oleh Detik.com berjudul:" PDIP Bantah Soal Rp $5 \mathrm{M}$ dari Penyuap Eks Walkot Kendari", (7 September 2018) menunjukkan bahwa bingkai utamanyanya sebagai define problems atau problem identification Detik.com secara lugas PDIP membantah kesaksian Hasmun Hamzah mengenai perkara suap yang diduga diberikan kepada mantan Wali Kota Kendari Asrun. Sementara kalau dilihat dari diagnose causes atau causal interpretation (perkiraan penyebab masalah), maka penyebab masalah ini adalah karena
Sekjen PDIP Hasto Kristiyanto membantah bahwa uang yang diberikan adalah mahar politik.

Untuk pembahasan make moral judgement atau moral evaluation (penilaian atas moral), Detik.com menunjukkan bahwa media berulang kali menekankan pandangan PDIP bahwa uang yang diterima adalah dengan prinsip gotong royong. Namun kemudian Detik.com memberitakan bahwa Hasmun terbukti bersalah dan divonis 2 tahun penjara dan denda Rp 200 juta subsider 3 bulan kurungan. Pada bagian treatment recommendation (rekomendasi penyelesaian masalah), pada elemen ini tampak pihak jurnalis Detik.com tidak memberikan rekomendasi yang jelas atas kasus tersebut. Detik.com sebagai bagian dari media yang bergabung dalam Transcorp, menunjukan posisinya yang juga seolah bersikap netral, Meski secara kasat mata dalam berita yang ditulis, menunjukan sudah ada ketok palu atas pelaku korupsi.

Analisa lainnya yakni pada Liputan6. com dengan judul "Polisi Ogan Komering Hulu Awasi Praktek Politik Uang di Pilkada Sumsel" (21 April 2018). Liputan6. com yang ternyata mengutip beritanya dari kantor berita Antara, mencoba menyajikan bingkai utamanya/ master framenya dengan define problems atau problem identification bahwa Polisi OKU Awasi Politik Uang di Pilkada Sumsel dan mengajak Kapolres OKU mengajak masyarakat untuk menghindari politik uang agar tercipta Pilkada Sumsel jurdil. Pada diagnose causes atau causal interpretation (perkiraan penyebab masalah), maka Liputan6.com menyampaikan pernyataan Kapolres dan juga diulang dengan pernyataan 
medianya bahwa banyak calon kepala daerah yang melakukan politik uang untuk memperoleh suara terbanyak. Pada pembahasan make moral judgement atau moral evaluation (penilaian atas moral) Liputan6.com hanya mengutip pernyataan Kapolres bahwa menurut Kapolres OKU, Politik uang penting untuk dihindari karena ada pidana bagi yang menerima maupun memberikan. Sementara pada treatment recommendation (rekomendasi penyelesaian masalah), tampak bahwa pihak jurnalis tidak memberikan penilaian maupun juga tidak memberikan rekomendasi penyelesaian masalah. Hal ini dikarenakan Liputan6.com hanya bener-bener mengutip apa adanya dari para narasumber, dalam hal ini dari Kapolres OKU. Liputan6.com sebagai bagian dari KapanLagi Network dengan 50\% dimiliki sahamnya oleh PT. Kreatif Media Karya yang masih berafiliasi dengan SCTV dan Indosiar, menunjukkan posisi yang juga netral dalam isu-isu pemberitaan politik uang di media mereka.

Pemberitaan di Kompas.com yang bertajuk: "Bawaslu Proses 35 Kasus Dugaan Politik Uang di Pilkada 2018, Terbanyak di Sulsel". (27 Juni 2018). Master frame atau bingkai utama dari pemberitaan Kompas.com pada point define problems atau problem identificationnya bahwa Bawaslu mencatat terdapat 35 kasus politik uang pada tingkat Kabupaten dan Kota pada Pilkada 2018 yang akan ditindak lanjuti, dengan kasus terbanyak di Sulsel. Kemudian apabila dilihat dari diagnose causes atau causal interpretation (perkiraan penyebab masalah), maka penyebab masalah adalah banyaknya kasus pada Pilkada. Bahwa lebih dari 400 an ratus data kasus yang diperoleh dari Bawaslu Daerah Kabupaten/Kota, namun di sisi lain, seolah hanya ada 35 kasus yang akan diproses oleh Bawaslu RI. Kemudian pada pembahasan make moral judgement atau moral evaluation (penilaian atas moral), pihak jurnalis Kompas.com tidak secara tegas menunjukkan penilaian atas moral yang ada dari pemberitaan tersebut. Jurnalis menginformasikan ratusan kasus yang ditemukan oleh Bawaslu. Kemudian pada treatment recommendation (rekomendasi penyelesaian masalah), pada elemen ini pihak jurnalis Kompas.com tidak memberikan rekomendasi atas isu tersebut. Pemberitaannya hanya seolah menampilkan data-data, namun tidak menjelaskan bagaimana sesungguhnya hubungan antara banyaknya temuan kasus oleh Bawaslu dan proses kasus tersebut akan ditindaklanjuti. Kompas. com sebagai media yang menjadi bagian dari Kompas - Gramedia grup, tampak memiliki sikap yang tidak jauh berbeda dengan media lainnya. Meski memiliki banyak data, dan bisa memberikan kritik kepada pihak yang diberitakan, namun prinsip kehati-hatian, sangat mendominasi bingkai setiap pemberitaannya.

Sementara itu pada pemberitaan terakhir lainnya yang dianalisis adalah pada Sindonews.com dengan judul: "Dituntut 36 bulan, Terdakwa Minta Aktor Money Politic Lahat Diadili" (20 Juli 2018). Sindonews.com menyajikan bingkai utamanya/ master framenya dengan define problems atau problem identification yakni Terdakwa kasus politik uang Pilkada kabupaten Lahat mendesak agar seluruh aktor utama politik uang di Pilkada Lahat turut diadili. Pada 
diagnose causes atau causal interpretation (perkiraan penyebab masalah), jurnalis menjelaskan bahwa JPU (Jaksa Penuntut Umum) didampingi Pisum Kejari Lahat menuntut terdakwa politik uang Pilkada Kabupaten Lahat 36 bulan penjara dan denda 200juta. Yang menyebabkan si terdakwa tidak mau dihukum sendirian. Pada pembahasan make moral judgement atau moral evaluation (penilaian atas moral), Sindonews.com tampak mencoba menggambarkan masif-nya jumlah kasus politik uang di Lahat menandakan bahwa terdapat banyak aktor dibalik kasus tersebut. Pada treatment recommendation (rekomendasi penyelesaian masalah), tampak bahwa pihak jurnalis tidak memberikan rekomendasi penyelesaian masalah. Hal ini dikarenakan tampak bersikap berhati-hati atas intrepertasi pemberitaan, hanya menyampaikan kutipan dari sejumlah tokoh nasional yang mendesak Bawaslu agar menyelesaikan kasus tersebut. Dilihat dari kepemilikan medianya, maka Sindonews.com yang merupakan bagian dari bisnis MNC Media Invesment (milik Hary Tanoesoedibjo), bisa dipastikan juga tidak akan memberikan pembingkaian yang "ditakutkan" terlalu menyudutkan pihak tertentu.

Secara ringkas pembahasan lengkap dapat dilihat dalam table berikut ini:

Tabel 3. Analisis Framing Media pada 5 Portal Berita Online

\begin{tabular}{|c|c|c|c|c|c|}
\hline $\begin{array}{l}\text { Analisa } \\
\text { Framing }\end{array}$ & Tribunnews.com & Detik.com & Liputan6.com & Kompas.com & $\begin{array}{l}\text { Sindonews. } \\
\text { com }\end{array}$ \\
\hline $\begin{array}{l}\text { Problem } \\
\text { Identification } \\
\text { (peristiwa } \\
\text { dilihat sebagai } \\
\text { apa) }\end{array}$ & $\begin{array}{l}\text { Kapolri } \\
\text { menyatakan ada } \\
25 \text { kasus politik } \\
\text { uang dalam } \\
\text { Pilkada serentak } \\
2018 \text { di depan } \\
\text { rapat kerja } \\
\text { dengan Komisi III } \\
\text { DPR RI. }\end{array}$ & $\begin{array}{l}\text { PDIP } \\
\text { membantah } \\
\text { kesaksian } \\
\text { Hasmun } \\
\text { Hamzah } \\
\text { mengenai } \\
\text { perkara suap } \\
\text { yang diduga } \\
\text { diberikan } \\
\text { kepada } \\
\text { mantan Wali } \\
\text { Kota Kendari } \\
\text { Asrun. }\end{array}$ & $\begin{array}{l}\text { Polisi OKU } \\
\text { Awasi Politik } \\
\text { Uang di Pilkada } \\
\text { Sumsel dan } \\
\text { mengajak } \\
\text { Kapolres OKU } \\
\text { mengajak } \\
\text { masyarakat } \\
\text { untuk } \\
\text { menghindari } \\
\text { politik uang } \\
\text { agar tercipta } \\
\text { Pilkada Sumsel } \\
\text { jurdil. }\end{array}$ & $\begin{array}{l}\text { Bawaslu } \\
\text { mencatat } \\
\text { terdapat } \\
35 \text { kasus } \\
\text { politik uang } \\
\text { pada tingkat } \\
\text { Kabupaten } \\
\text { dan Kota } \\
\text { pada Pilkada } \\
2018 \text { yang } \\
\text { akan ditindak } \\
\text { lanjuti. } \\
\text { Dengan kasus } \\
\text { terbanyak di } \\
\text { Sulsel. }\end{array}$ & $\begin{array}{l}\text { Terdakwa } \\
\text { kasus politik } \\
\text { uang Pilkada } \\
\text { kabupaten } \\
\text { Lahat } \\
\text { mendesak agar } \\
\text { seluruh aktor } \\
\text { utama politik } \\
\text { uang di Pilkada } \\
\text { Lahat turut } \\
\text { diadili. }\end{array}$ \\
\hline $\begin{array}{l}\text { Causal } \\
\text { interpretation } \\
\text { (siapa } \\
\text { penyebab } \\
\text { masalah) }\end{array}$ & $\begin{array}{l}\text { Jurnalis tidak } \\
\text { menjelaskan } \\
\text { apa yang } \\
\text { menyebabkan } \\
\text { Kapolri } \\
\text { mengeluarkan } \\
\text { pernyataan } \\
\text { tersebut. }\end{array}$ & $\begin{array}{l}\text { Sekjen } \\
\text { PDIP Hasto } \\
\text { Kristiyanto } \\
\text { membantah } \\
\text { bahwa } \\
\text { uang yang } \\
\text { diberikan } \\
\text { adalah } \\
\text { mahar } \\
\text { politik. }\end{array}$ & $\begin{array}{l}\text { Banyak Calon } \\
\text { kepala daerah } \\
\text { yang melakukan } \\
\text { politik } \\
\text { uang untuk } \\
\text { memperoleh } \\
\text { suara terbanyak }\end{array}$ & $\begin{array}{l}\text { Bahwa lebih } \\
\text { dari } 400 \text { an } \\
\text { ratus data } \\
\text { kasus yang } \\
\text { diperoleh } \\
\text { dari Bawaslu } \\
\text { Daerah } \\
\text { Kabupaten/ } \\
\text { Kota hanya } \\
\text { ada } 35 \text { kasus } \\
\text { yang akan di } \\
\text { proses oleh } \\
\text { Bawaslu RI. }\end{array}$ & $\begin{array}{l}\text { JPU } \\
\text { didampingi } \\
\text { Pisum } \\
\text { Kejari Lahat } \\
\text { menuntut } \\
\text { terdakwa } \\
\text { politik uang } \\
\text { Pilkada } \\
\text { Kabupaten } \\
\text { Lahat } 36 \text { bulan } \\
\text { penjara dan } \\
\text { denda 200juta. }\end{array}$ \\
\hline
\end{tabular}


Dari materi di atas bisa dilihat bahwa para jurnalis tidak bisa melepaskan diri dari kebijakan para pemilik media yang bersangkutan. Media online cenderung memiliki pola yang sama yakni menekankan pada persoalan kecepatan penyampaian berita, sehingga sering kali abai terhadap akurasi (ketepatan berita). Disisi lain, semua media online yang diteliti tidak menunjukkan upaya untuk memberikan rekomendasi secara real atas permasalahan yang terjadi berkaitan dengan politik uang. Hal ini yang membedakan pemberitaan media online dengan media cetak yakni berkaitan dengan kedalaman berita dan upaya memberikan solusi serta rekomendasi bagi pembacanya.

\section{Simpulan}

Kesimpulan penelitian ini menunjukan bahwa:

1. Secara umum media memiliki framing yang tidak jauh berbeda satu sama lain. Meski pemilik media dan kebijakan media berbeda, namun rata-rata media menyajikan berita politik uang di Pilkada dengan "tone" nada berita yang tidak jauh berbeda, rata-rata netral. Tidak bersikap menentang ataupun mendukung praktik politik uang. Hal ini menjadi sebuah kondisi yang memprihatinkan bagi keberadaan media online sebagai representasi pers Indonesia. Pers Indonesia sudah seharusnya bersikap tegas dalam pemberitaan yang menekankan pada objektifitas untuk kesejahteraan masyarakat.

2. Beberapa media mengutamakan pemberitaan yang bersifat nasional, dan ada yang bersifat lokal/ kedaerahan. Berita dengan tema politik uang, yang diangkat bisa yang bersifat nasional namun juga bersifat lokal, sesuai dengan situasi pilkada.

3. Hanya saja pada bagian treatment recommendation - saran perbaikan, tampak semua media tidak secara tegas menunjukan sikap keberpihakannya pada regulasi dan etika yang secara jelas melarang praktik politik uang dalam Pilkada. Semua media seolah tidak memberikan gambaran atas sangsi moral atas para pelaku politik uang. Kondisi ini tentu saja tidak terlalu menggembirakan, terlebih fungsi pemberitaan sebagai gate keeper masyarakat tidak berjalan dengan maksimal.

Penelitian ini memiliki keterbatasan yakni hanya meneliti pada 5 media online utama yang memiliki banyak pembaca, belum menjangkau lebih luas dan lebih banyak lagi pemberitaan media online lainnya. Sehingga diperlukan riset lebih lanjut untuk meningkatkan hasil penelitiannya. Selain itu juga perlu dikaji dan diteliti dari sisi wawancara mendalam pada para pengelola media untuk mengetahui lebih lanjut kebijakan dan campur tangan pemilik media di masing-masing media online tersebut saat memproduksi dan membingkai sebuah berita.

Rekomendasi dari hasil penelitian ini adalah, media dalam hal ini jurnalis dan redaksi, harus lebih diperkuat pemahamannya tentang fungsi mereka sebagai gate keeper, dan penjaga pilar demokrasi. Menunjukkan bahwa sudah menjadi keharusan media untuk lebih tegas membingkai pemberitaan ke arah yang memperjuangkan kepentingan masyarakat. Dalam hal ini anti politik uang sudah menjadi informasi dan berita yang wajib disebarluaskan oleh media. 


\section{DAFTAR PUSTAKA}

Balnaves, Mark., Stephanie Hemelryk Donald \& Brian Shoesmith. (2009). Media Theories \& Approaches; A Global Perspective. London: Palgrave Macmillan.

Burton, Graeme. (2009). Media and Society; Critical Perspectives.India: Rawat Publication.

Cross, S. \& Lockyer, S. (2006). Dynamics of Partisan Journalism, Journal of Journalism Studies, 7:2, 274-291, DOI: 10.1080/14616700500533585

D’angelo, Paul. Jim A. Kuypers. (2010). Doing News Framing Analysis; Empirical and Theorical Perspective. New York : Routledge.

Entman, R. M. (2003). Projections of Power: Framing News, Public Opinion, and U.S. Foreign Policy. Chicago, USA: University of Chicago Press.

Eriyanto. 2011. Analisis Isi: Pengantar Metodologi untuk Penelitian Komunikasi dan Ilmu-IImu lainnya. Jakarta. Kencana.

Ismail, T. (2018, Juli 19). Polri Usut 25 Kasus Politik Uang dalam Pilkada Serentak 2018. Tribun News. Diakses dari http://www.tribunnews.com

Jurnaliston, R. (2018, Juni 27). Bawaslu Proses 35 Kasus Dugaan Politik Uang di Pilkada 2018, Terbanyak di Sulsel. Kompas.com. Diakses dari http:// nasional.kompas.com

McCombs, M., \& Reynolds, A. (2009). How the news shapes our civic agenda. In J. Bryant \& M. B. Oliver (Eds.), Media effects: Advances in theory and research (pp. 1-16). New York, NY: Lawrence Erlbaum Associates.

Mishra, S. (2013) Projections of Power, News Framing, and India's 2010 Commonwealth Games, Howard Journal of Communications, 24:2, 178-193, DOI:10.1080/10646175.2013.776412

Nadeau, R., Cloutier, E., \& Guay, J.-H. (1993). New Evidence About the Existence of a Bandwagon Effect in the Opinion Formation Process. International Political Science Review, 14(2), 203-213. doi:10.1177/019251219301400204

Nugroho, W. (2018, Juli 20). Dituntut 36 Bulan, Terdakwa Minta Aktor Money Politic Pilkada Lahat Diadili. SINDOnews. Diakses dari http://daerah. sindonews.com

Nurhajati, L. (2015). Pola Konsumsi Media Generasi Z di Indonesia. Prosiding Konferensi IMRAS (Indonesia Media Research Awards and Summit) SPS Serikat Penerbit Seluruh Indonesia 2015.

NN, Liputan6. (2018, April 21). Polisi Ogan Komering Ulu Awasi Praktik Politik Uang di Pilkada Sumsel. Liputan6. Diakses dari http://www.liputan6.com

Putri, ZA. (2018, September 07). PDIP Bantah soal Rp 5 M dari Penyuap Eks Walkot Kendari. detikNews. Diakses dari http://www.detik.com

Sobur, A. (2004). Analisis Teks Media: Suatu Pengantar untuk Analisis Wacana. Analisis 
Semiotik dan Analisis Framing. Bandung: Rosda Karya.

Straubhaar, Joseph \& Robert LaRose. (2006). Media Now: Understanding Media, Culture and Technology. 5th edition. USA: Thomson Wadsworh.

Willnat . L, Weaver, D.H. \& Choi, J. (2013), The Global Journalist in the Twenty-First Century, Journal of Journalism Practice, 7:2, 163-183, DOI: 10.1080/17512786.2012.753210

54 Jurnal Adhyasta Pemilu 